\title{
Bait attraction affects the performance of remote underwater video stations in assessment of demersal fish community structure
}

\author{
Euan S. Harvey ${ }^{1,4, *}$, Mike Cappo ${ }^{2}$, James J. Butler ${ }^{1}$, Norm Hall ${ }^{3}$, Gary A. Kendrick ${ }^{1,4}$ \\ ${ }^{1}$ School of Plant Biology (Botany M090), University of Western Australia, 35 Stirling Highway, Crawley, \\ Western Australia 6009, Australia \\ ${ }^{2}$ Australian Institute of Marine Science, PMB 3, Townsville MC, Queensland 4810, Australia \\ ${ }^{3}$ Centre for Fish and Fisheries Research, School of Biological Sciences and Biotechnology, Murdoch University, Murdoch, \\ Western Australia 6150, Australia \\ ${ }^{4}$ CRC for Coastal Zone, Estuary and Waterway Management, School of Plant Biology (Botany M090), \\ University of Western Australia, 35 Stirling Highway, Crawley, Western Australia 6009, Australia
}

\begin{abstract}
Discriminating marine fish assemblages at broad scales can be difficult because of heterogeneity within their habitats, variability in patterns of behaviour and abundance of fish between habitats, and sampling biases in extractive fishing techniques when used across a range of habitats. Remote underwater video stations have recently been developed to help overcome these problems, but the use of bait as an attractant raises questions about bias towards scavengers and predators in samples of fish communities. We compared the ability of baited and unbaited underwater video stations to discriminate between fish assemblages inhabiting distinct benthic habitats in temperate and tropical continental shelf waters in Australia, to help test whether the bait attracted predatory and scavenging species to the video in disproportionate numbers in comparison to other trophic groups, such as herbivores. Data from baited video cameras displayed a clearer discrimination in constrained canonical analysis of principal coordinates of fish assemblages between marine habitats in both tropical and temperate environments. Analysis of the key trophic groups indicated that bait attracted greater numbers of predatory and scavenging species without decreasing the abundances of herbivorous or omnivorous fishes. There was greater similarity between replicate samples from baited video within habitats, implying that the use of bait will provide better statistical power to detect spatial and temporal changes in the structure of fish assemblages and the relative abundances of individual species within them.
\end{abstract}

KEY WORDS: Demersal fish assemblages · Underwater video stations $\cdot$ Bait $\cdot$ Remote sampling Resale or republication not permitted without written consent of the publisher

\section{INTRODUCTION}

In topographically complex habitats, the relative abundance and distribution of individual species of fish is difficult to assess comprehensively. This is due to the heterogeneity of their habitats, variability in patterns of fish behaviour and abundance, and sampling bias in the techniques available. Numerous comparative studies have documented bias and selectivity among sampling methods (e.g. Willis et al. 2000, Watson et al. 2005). The coefficients of variation for some extractive techniques, such as fish trapping, can be so high that the power to detect large changes in sample means is weak, requiring levels of replication that would be unacceptable in areas such as marine parks (Williams et al. 1997, Cappo et al. 2003).

Underwater visual surveys by SCUBA divers in shallow waters, and by observers from submersibles in deeper waters, have enabled density estimates to be made for a variety of species in a range of habitats (e.g. Samoilys \& Carlos 2000, Yoklavich et al. 2000). However, these surveys can be seriously biased for some 
'shy' or cryptic species (Watson et al. 1995, Kulbicki 1998, Willis \& Babcock 2000, Stewart \& Beukers 2000, Watson et al. 2005). Other important drawbacks of these methods are the depth limitations of diver surveys and the prohibitive costs and limited availability of submersibles.

More recently, remotely operated video stations have been used to minimise the biases introduced by the presence of SCUBA divers (Willis \& Babcock 2000, Willis et al. 2000, Westera et al. 2003) and those biases associated with gear selectivity inherent in baited trapping and hook-and-line surveys (Ellis \& DeMartini 1995, Cappo et al. 2004). These studies followed the development of protocols to count and measure scavengers in abyssal depths using time-lapse still cameras or video cameras (Priede et al. 1990, 1994, Priede \& Merrett 1996). Video-based techniques are now proving particularly useful in assessing the effects of marine protected areas, because they are relatively non-destructive, cost effective and not limited by depth (see Cappo et al. 2003 for review, Westera et al. 2003, Denny \& Babcock 2004, Denny et al. 2004).

Over recent years the image quality of video has improved, and the initial capital investment has decreased sufficiently that it is now affordable for researchers to deploy multiple remote underwater video stations (RUVS) simultaneously, which greatly increases the potential replication and spatial coverage of sampling. Remote video sampling is non-extractive and, unlike research trawling, has minimal impacts on benthos. This allows information to be repeatedly gathered in protected areas in an acceptable manner. Remote underwater video stations can be accurately deployed into very rugose habitats, such as boulder fields, coral and limestone reefs, kelp and seagrass beds. The deployment and retrieval of a small frame causes only small, localised habitat damage in fragile environments and does not harm the target fauna.

A number of studies have used bait in conjunction with video cameras to attract fish into the field of view (Ellis \& DeMartini 1995, Priede \& Merrett 1996, Willis $\&$ Babcock 2000, Willis et al. 2000, Westera et al. 2003, Cappo et al. 2004, Denny \& Babcock 2004, Denny et al. 2004, Watson et al. 2005). Only 1 study (Watson et al. 2005) has tested for differences between baited and unbaited camera stations in the diversity and relative abundance of fishes.

It might be predicted that samples from baited RUVS may be biased towards predatory or scavenging species and exclude herbivorous or omnivorous species. For example, striking differences have been recorded in catches from baited and unbaited fish traps (Newman 1990). Such dynamics would severely bias the discrimination of fish assemblages in temperate and tropical biodiversity surveys using RUVS methods.
This study compares the ability of baited and unbaited RUVS to discriminate among fish assemblages inhabiting distinct benthic habitats in shallow shelf waters of temperate and tropical Australia. We also explored the potential bias of using bait as an attractant by testing for differences in the diversity $\left(N_{\mathrm{sp}}\right)$ and relative abundance $(\operatorname{Max} N)$ of fishes belonging to different trophic groups recorded by baited and unbaited RUVS.

\section{METHODS AND MATERIALS}

Temperate sampling. Four baited and 4 unbaited RUVS were deployed in each of 6 benthic habitats (a total of 48 samples) within Esperance Bay, South Western Australia $\left(34^{\circ} \mathrm{S}, 122^{\circ} \mathrm{E}\right)$ in September 2002. The locations of deployments were selected from a habitat map of benthic coverage in the area. The 6 habitat categories sampled were: seagrass beds (SG), Ecklonia radiata macroalgal beds (Eck), other macrophytes (OM), deep reef (DR), rhodolith beds (Rhod) and sand (S). The seagrass habitat was characterised by a 60 to $100 \%$ cover of Posidonia spp. between depths of 10 and $16 \mathrm{~m}$. Ecklonia and other macrophyte habitats were found on sloping granite reefs between depths of 3 and $28 \mathrm{~m}$ and had a $60 \%$ cover or greater of the small kelps Ecklonia radiata (Eck), or Sargassum spp. and Cystophora spp. (OM). Deep reefs comprised reefs of granite bedrock at depths $>30 \mathrm{~m}$, and were characterised by a sparse cover of macroalgae or sponges. Rhodolith and sand habitats had low relief, with an $80 \%$ or greater cover of rhodoliths or sand, and were always deeper than $30 \mathrm{~m}$.

Within each habitat, four $1 \mathrm{~h}$ recordings were made for both baited and unbaited RUVS. At a site, unbaited and baited RUVS were set in a sequence, with unbaited RUVS being deployed first. We allowed $20 \mathrm{~min}$ to elapse before baited deployments were made at the same site. This minimum time was based on results from a prior study (E. Harvey unpubl. data), which showed that deploying and retrieving the camera system influenced the fish assemblages present for up to 4 min after deployment and retrieval in some habitats. Sampling was completed between 08:30 and 15:30 h to avoid crepuscular changes in fish behaviour. Up to 4 RUVS were deployed at any one time, at a separation of at least $500 \mathrm{~m}$ between stations to minimise the possibility of attraction of individual fish from one RUVS to another. Recordings were made using 4 stereo-video systems (see Harvey \& Shortis 1996 and Harvey et al. 2002a for design and measurement procedures), using either Sony TRV900E or TRV15 digital camcorders within waterproof housings. Bait arms made of $20 \mathrm{~mm}$ plastic conduit with a standard rock lobster bait canister fastened to one end were attached to the stereo-video 
frame and detached during and after deployment (see Watson et al. 2005 for a description). The bait canister was approximately $1.25 \mathrm{~m}$ from the cameras. We used $1 \mathrm{~kg}$ of crushed South American pilchards Sardinops sagax placed in the bait bag for each deployment of baited RUVS. Unbaited RUVS also had a conduit and bait bag attached to the frame, but used clean bait canisters that had never had bait placed in them. Fish could be identified at up to $7 \mathrm{~m}$ from the cameras. At this distance we had a horizontal field of view with stereo coverage of $14.59 \mathrm{~m}$ and sampled an area of $51 \mathrm{~m}^{2}$.

Tropical sampling. Six single camera RUVS were deployed about 300 to $450 \mathrm{~m}$ apart along transects within habitat types in an alternating sequence of baited and unbaited units. The distance between sequential tropical stations was slightly less than temperate stations because they were set around reefs and in channels along the tracks of towed video cameras where the benthos was known. These tracks were relatively short and did not allow wider separation of the 6 stations. The stations consisted of a galvanized roll-bar frame enclosing a simple camera housing made from PVC pipe with acrylic front (dome) and rear ports. Stabilizing arms and bait arms $(20 \mathrm{~mm}$ plastic conduit) were attached during deployment. The bait arm had two $50 \mathrm{~mm}$ square scale grids at both ends of a $350 \mathrm{~mm}$ plastic mesh bait canister containing $1 \mathrm{~kg}$ of crushed pilchards Sardinops neopilchardus (see Cappo et al. 2004 for diagram). Sony Hi-8 Handicams (Model TR516E) with wide-angle lenses (Hama $0.5 \times$ ) were used in the housings.

Deployments $(1 \mathrm{~h})$ of baited and unbaited RUVS were made in the central section of the Great Barrier Reef Marine Park (around latitude $18^{\circ} \mathrm{S}$ ) near Calliope and Curacoa Channels in the Palm Islands, at Robbery Shoals offshore from the Palm Islands, and around the mid-shelf reefs and shoals of Rib Reef, Kelso Shoals and Davies Reef. The habitat types were mapped prior to deployment of the RUVS by use of a towed underwater television camera linked to a GIS, and were checked directly from the field of view of the video stations. The habitat categories recognised were: 'megabenthos' (including macroalgal beds, corals, sponge and gorgonian gardens; 26 to $36 \mathrm{~m}$ ), 'fine sand' (including mud; 17 to $36 \mathrm{~m}$ ), 'coarse sand' (including rubble; 27 to $47 \mathrm{~m}$ ) and 'near benthos' (30 to $40 \mathrm{~m}$ ). The 'near benthos' category covered sets where the RUVS landed on sand, but significant patches of 'megabenthos' were seen in the field of view on the seabed, or during the deployment or retrieval. We deployed 6 baited and 6 unbaited RUVS in each habitat.

Analysis of video tapes. Tape analysis commenced when the RUVS settled on the seabed. For each species seen in both tropical and temperate RUVS we recorded the maximum number seen together at any one time on the whole tape $(\operatorname{Max} N)$. We used $\operatorname{Max} N$ as a conservative estimator of the number of fish seen on a RUVS drop, because we were concerned that individual fish might be counted repeatedly when leaving and then re-entering the field of view during tape analysis. The $\operatorname{Max} N$ of our study is the same as the $n_{\text {peak }}$ of Priede et al. (1994), the MAXNO of Ellis \& DeMartini (1995) and the MAX of Willis \& Babcock (2000). This estimator will result in separate visits by different individuals of the same species to a RUVS being recorded as $\operatorname{Max} N=1$. Max $N$ will give conservative estimates of abundance in high-density areas. Therefore, any differences detected between treatments are also likely to be conservative (Willis et al. 2000, Cappo et al. 2003).

Trophic groups. All species of fish and elasmobranchs recorded on RUVS drops were assigned to 1 of 10 trophic groups, based on their feeding habits and functional morphology. This information was derived from 'FishBase' (Froese \& Pauly 2006), and local fish identification guides. The groups were classified by the predominance of prey types into (1) 'herbivores', (2) 'corallivores', (3) 'zooplanktivores', (4) 'piscivores' and (5) 'invertebrate carnivores'. Further groupings were recognised by the predominance of food in mixtures into (6) 'algae/invertebrates', (7) 'invertebrates/algae' and (8) 'sponges/invertebrates'. Carnivores were also classified by the size and range of items eaten. (9) 'Macro-invertebrate carnivores', like larger rays, eat large items such as cephalopods, molluscs and crustaceans. (10) 'Generalist carnivores' were recognised on the basis of a wide range of fishes and invertebrates taken from various positions in the water column. Very large 'generalist macrocarnivores', such as larger sharks, were incorporated into the 'generalist carnivore' group because of their rarity in video records.

Statistical analysis. We used a 2-way non-parametric multivariate analysis of variance (PERMANOVA) (Anderson 2001, Anderson \& Robinson 2003, Anderson \& Gorley 2007) to test for differences in the fish assemblages sampled by baited and unbaited RUVS. For the temperate data our experimental design consisted of 2 factors: 'bait treatment' (Treatment; 2 levels, fixed) and 'habitat' (Habitat; 6 levels, fixed) with 4 replicates. We used the same model for tropical data, with the exception that habitat had 4 levels rather than 6 and we had 6 replicates. We transformed the data using $\ln (x+1)$ and used a Bray-Curtis dissimilarity measure. For each term in the analysis, 4999 permutations of the raw data units were computed to obtain p-values. For the temperate assemblage data, we excluded a schooling carangid (Pseudocaranx dentex) from the analysis. This was because $P$. dentex was often recorded in schools resulting in $\operatorname{Max} N_{i}>100$ (where $i$ represents the species), and this variance dominated the analysis. 
We also analysed the effect of treatment after removing the effect of habitat and depth. We used PERMANOVA with a single factor (Treatment) with habitat and depth treated as covariables in the model. To investigate the proportion of variance that each of the variables (treatment, habitat and depth) contributed to the assemblage structure we undertook a distancebased multivariate analysis for a linear model (DISTLM) (Anderson \& Gorley 2007) using forward selection.

To visually compare the assemblages identified by baited and unbaited RUVS, a plot of the principal coordinates for both temperate and tropical fish assemblages was constructed from a constrained canonical analysis of principal coordinates (CAP; Anderson \& Robinson 2003, Anderson \& Willis 2003).

We also tested for differences in the numbers of individuals and the numbers of species amongst treatments, and used non-parametric multivariate analysis of variance (PERMANOVA) (Anderson \& Millar 2004) due to the predominance of zeros and the variability between samples. This analysis does not assume normality or any other specified distribution. We have analysed the data using the model described above (4999 permutations), but, because we used only one variable at a time, the analysis was based on Euclidean distance (Anderson \& Millar 2004). For both the temperate and tropical data sets, we also analysed the numbers of individual fish (calculated as the sum of $\left.\operatorname{Max} N_{i}\right)$ and the numbers of species $\left(N_{\mathrm{sp}}\right)$ within each trophic group. The aim of this analysis was to determine if particular trophic groups were influenced more by bait, and if the use of bait attracted more species and more individuals. Eight of the 10 trophic groups were recorded in the temperate data, and 10, in the tropical data.

\section{RESULTS}

The temperate and tropical video samples produced a diverse species list, ranging from small pomacentrids of $<3 \mathrm{~cm}$ length to large sharks and rays of several metres in length. In 48 temperate samples, we recorded 1656 individuals from 63 species and 32 families. By contrast in the 48 RUVS set in the tropics, we recorded 1548 individuals from 211 species and 37 families.

\section{Assemblage data}

In both the temperate and tropical regions, there were significant differences in the fish assemblages recorded by baited and unbaited RUVS (Table 1). Significant differences between habitats were also recorded as a recurring theme throughout our results,
Table 1. PERMANOVA of $\ln (x+1)$-transformed abundance data for assemblage data sampled by baited and unbaited remote underwater video stations (RUVS) in 6 benthic habitats in temperate waters and 4 benthic habitats in tropical waters. Results are based on the Bray-Curtis dissimilarity measure. Treatment ( $\mathrm{T}$; baited or unbaited) and Habitat $(\mathrm{H})$ are fixed factors. The $\mathrm{p}$-values were obtained using 4999 permutations of the given permutable units for each unit. Bold values: $p<0.05$

\begin{tabular}{|lrrrr|}
\hline Source & df & \multicolumn{1}{c}{ MS } & $F$ & \multicolumn{1}{c|}{$p$} \\
\hline Temperate & & & & \\
$\mathrm{T}$ & 1 & 9668 & 3.5 & $\mathbf{0 . 0 0 2}$ \\
$\mathrm{H}$ & 5 & 11765 & 4.3 & $<\mathbf{0 . 0 0 1}$ \\
$\mathrm{T} \times \mathrm{H}$ & 5 & 2945 & 1.0 & 0.330 \\
Residual & 36 & 2725 & & \\
Total & 47 & & & \\
Tropical & & & & \\
$\mathrm{T}$ & 1 & 7464 & 2.14 & $\mathbf{0 . 0 0 5}$ \\
$\mathrm{H}$ & 5 & 11314 & 3.25 & $<\mathbf{0 . 0 0 1}$ \\
T $\times$ H & 5 & 6840 & 1.96 & $<\mathbf{0 . 0 0 1}$ \\
Residual & 36 & 3478 & & \\
Total & 47 & & & \\
\hline
\end{tabular}

but will not be interpreted here, as they are the focus of the analysis and interpretation of more comprehensive data sets. In the tropical data set, there was a significant Treatment $\times$ Habitat interaction (Table 1 ). This was caused by the lack of significant differences in the fish assemblages sampled by baited and unbaited RUVS in coarse sand and near benthos habitats, combined with the significant differences detected amongst assemblages detected in fine sand and megabenthos habitats.

Treatment was still a significant effect after extracting the effect of habitat and depth for both temperate (Treatment $_{(1,47)}, \mathrm{MS}=10140$, pseudo- $F=5.48, \mathrm{p}<$ 0.001 ) and tropical (Treatment $(1,86), \mathrm{MS}=8636.3$, pseudo- $F=2.197, \mathrm{p}=0.003)$ data. In both analyses, the covariables were significant $(p<0.001)$. The DISTLM analysis revealed that treatment, habitat and depth all had significant influences on the structure of the fish assemblages sampled. For the temperate data, depth accounted for $15.4 \%$ of the variance, habitat for $11.5 \%$ and treatment for $8.1 \%$. For the tropical data, depth accounted for $3.4 \%$ of the variance, habitat for $6.35 \%$ and treatment for $3.3 \%$.

Plots of the principal co-ordinates from a CAP analysis for both temperate (Fig. 1A) and tropical (Fig. 1B) fish assemblages show that the use of bait allows greater discrimination between samples taken from different habitats, whilst increasing the similarity of samples taken within the same habitats. This was supported by the 'leave one out' allocation success (Anderson \& Willis 2003) for both temperate and tropical fish assemblages, which provides a statistical estimate of mis-classification error and demonstrates how distinct groups of sites or samples are in multivariate space (Anderson \& Willis 2003). Temperate assem- 
A

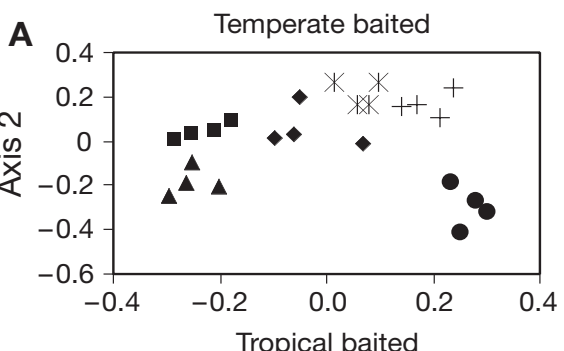

- Deep Reef

- Ecklonia

\ Other macrophytes

+ Rhodoliths

* Sand

- Seagrass

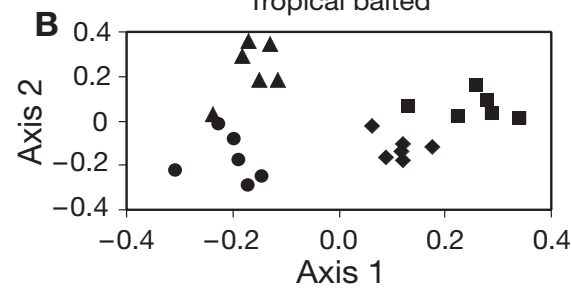

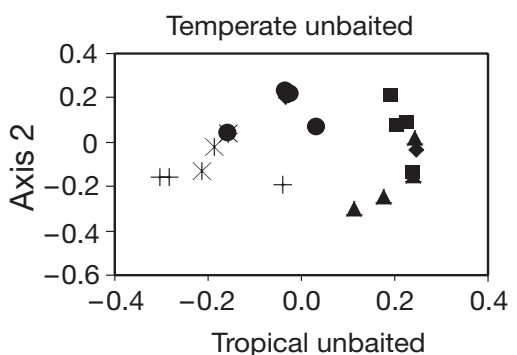

- Coarse Sand

- Fine Sand

A Megabenthos

- Near Benthos

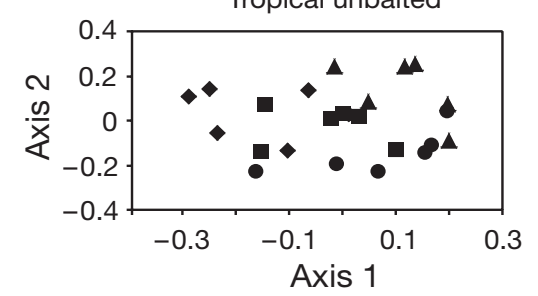

Fig. 1. (A) Temperate and (B) tropical assemblage: plots of the principal co-ordinates from a canonical analysis of principal coordinates. Temperate data were collected from 6 habitats using baited and unbaited remote underwater video $(\mathrm{N}=4$ within each habitat), with 4999 permutations of the data units. Tropical data were collected in 4 habitats using baited and unbaited remote underwater video ( $\mathrm{N}=6$ within each habitat), with 4999 permutations of the data units

blages had an allocation success of $54 \%$ with unbaited RUVS, which improved to $62.5 \%$ with bait. Tropical assemblages had an allocation success of $62.5 \%$ without bait, but $83 \%$ with bait.

\section{Numbers of individual fish and species sampled by baited and unbaited RUVS}

In both the temperate and tropical regions, there were significant differences in the numbers of individual fish (Table 2) and the numbers of species (Table 3) recorded by baited and unbaited RUVS. Significant differences amongst habitats were also recorded. Plots of the mean $\operatorname{Max} N_{i}$ (Fig. 2A) and mean number of spe-

Table 2. PERMANOVA of $\ln (x+1)$-transformed abundance data for the number of individual fish sampled by baited and unbaited RUVS in 6 benthic habitats in temperate waters and 4 benthic habitats in tropical waters. Results are based on Euclidean distance. Definitions and abbreviations, see Table 1.

Bold values: $\mathrm{p}<0.05$

\begin{tabular}{|lcccr|}
\hline Source & df & MS & $F$ & \multicolumn{1}{c|}{ p } \\
\hline Temperate & & & & \\
$\mathrm{T}$ & 1 & 15.450 & 17.453 & $<\mathbf{0 . 0 0 1}$ \\
$\mathrm{H}$ & 5 & 5.685 & 6.422 & $\mathbf{0 . 0 0 1}$ \\
$\mathrm{T} \times \mathrm{H}$ & 5 & 0.648 & 0.732 & 0.602 \\
Residual & 36 & 0.885 & & \\
Total & 47 & & & \\
Tropical & & & & \\
$\mathrm{T}$ & 1 & 15.953 & 23.871 & $\mathbf{< . 0 0 1}$ \\
$\mathrm{H}$ & 5 & 3.704 & 5.543 & $\mathbf{0 . 0 0 3}$ \\
T $\times$ H & 5 & 0.030 & 0.045 & 0.987 \\
Residual & 36 & 0.668 & & \\
Total & 47 & & & \\
\hline
\end{tabular}

cies $N_{\mathrm{sp}}$ (Fig. 2B) show that overall greater numbers of individuals and species were recorded by baited than unbaited RUVS in both temperate and tropical marine habitats.

\section{Temperate trophic groups}

A 2-way non-parametric multivariate analysis of variance (PERMANOVA) showed that statistically significant higher mean numbers of individuals (Max $N_{i}$; Fig. 3A) and species ( $N_{\mathrm{sp}}$, Fig. 3B) were recorded by baited RUVS for 5 of the 8 trophic groups (piscivores, generalist carnivores, macroinvertebrate carnivores, invertebrate carnivores and invertebrate/algae feed-

Table 3. PERMANOVA of $\ln (x+1)$-transformed data for the maximum number of species sampled by baited and unbaited RUVS in 6 benthic habitats in temperate waters and 4 benthic habitats in tropical waters. Results are based on Euclidean distance. Definitions and abbreviations, see Table 1. Bold values: $\mathrm{p}<0.05$

\begin{tabular}{|lcccr|}
\hline Source & df & MS & $F$ & \multicolumn{1}{c|}{ p } \\
\hline Temperate & & & & \\
$\mathrm{T}$ & 1 & 325.521 & 25.297 & $<\mathbf{0 . 0 0 1}$ \\
$\mathrm{H}$ & 5 & 230.921 & 17.945 & $<\mathbf{0 . 0 0 1}$ \\
$\mathrm{T} \times \mathrm{H}$ & 5 & 6.121 & 0.476 & 0.800 \\
Residual & 36 & 12.868 & & \\
Total & 47 & & & \\
Tropical & & & & \\
$\mathrm{T}$ & 1 & 2.277 & 9.379 & $\mathbf{0 . 0 0 3}$ \\
$\mathrm{H}$ & 5 & 2.879 & 11.857 & $<\mathbf{0 . 0 0 1}$ \\
$\mathrm{T} \times \mathrm{H}$ & 5 & 0.167 & 0.689 & 0.570 \\
Residual & 36 & 0.243 & & \\
Total & 47 & & & \\
\hline
\end{tabular}



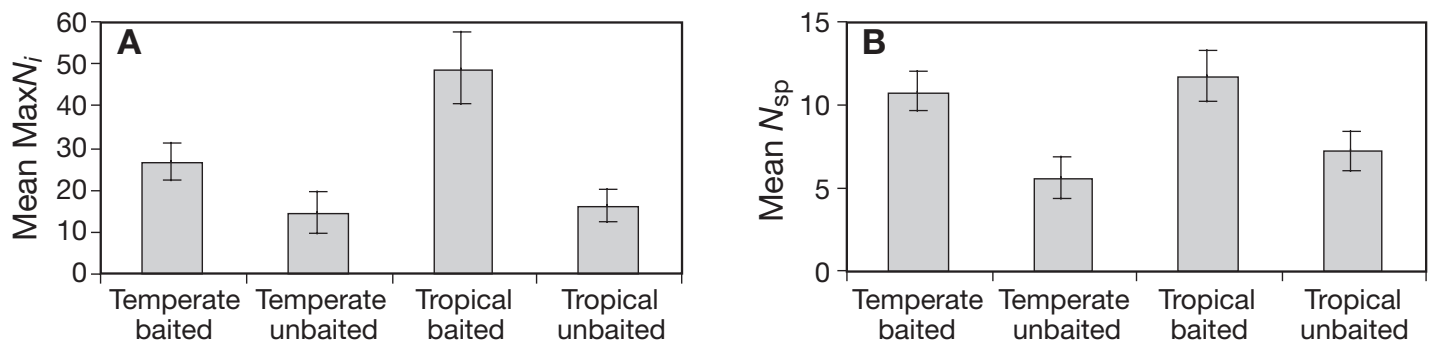

Fig. 2. (A) Mean number of individuals $\left(\operatorname{Max} N_{i}\right)$ and (B) mean number of species $\left(N_{\mathrm{sp}}\right)$ for baited and unbaited remote underwater video stations (RUVS) in temperate and tropical habitats; $\mathrm{N}=24$. Error bars $= \pm 1 \mathrm{SE}$
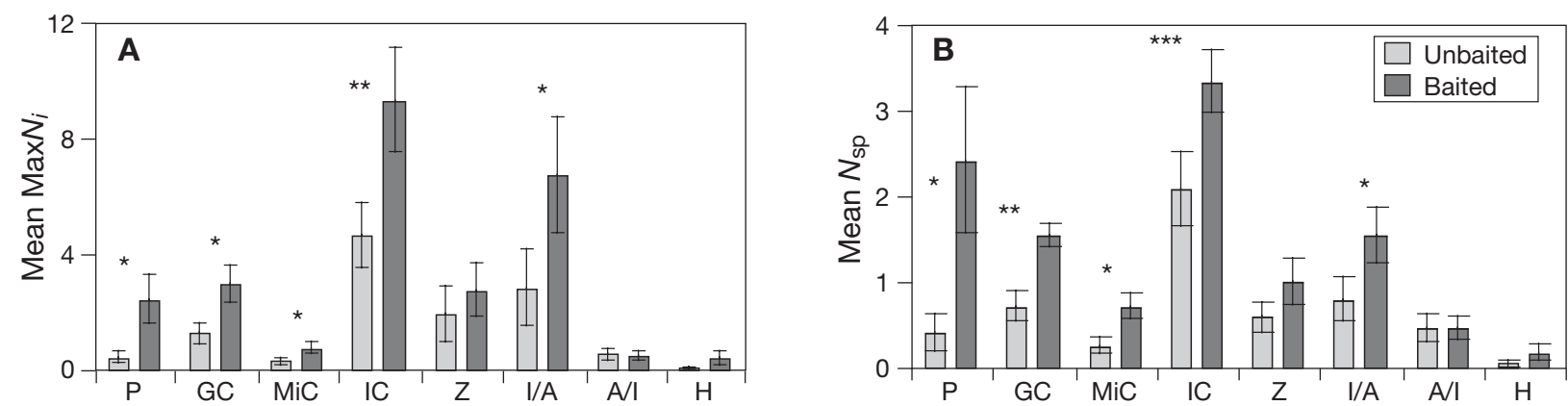

Fig. 3. Temperate assemblage: mean (A) $\operatorname{Max} N_{i}$ and (B) $N_{\mathrm{sp}}$ counted for both unbaited and baited RUVS for 8 trophic groups within 6 benthic habitats; $\mathrm{N}=4$. P: piscivore; GC: generalist carnivore; MIC: macroinvertebrate carnivore; IC: invertebrate carnivore; Z: zooplankton; I/A: invertebrates/algae; A/I: algae/invertebrates; H: herbivores. Error bars: \pm 1 SE. Asterisk indicates the level of significance for treatment (baited vs. unbaited). ${ }^{*} \mathrm{p}<0.05,{ }^{* *} \mathrm{p}<0.01,{ }^{* * *} \mathrm{p}<0.001$

ers, see Table 4, Fig. 3A,B) in comparison to unbaited RUVS. For both $\operatorname{Max} N_{i}$ and $N_{\mathrm{sp}}$, there were significant differences between habitats for all trophic groups, with the exception of piscivores and macroinvertebrate carnivores. There were significantly more individual generalist carnivores recorded in baited than unbaited RUVS.

There was also a significant Treatment $\times$ Habitat interaction for herbivores caused by a greater number of species and individuals of herbivorous fish recorded with bait in seagrass in comparison to other combinations of habitat and treatment. However, overall numbers of herbivores seen were low, and this outcome must be treated with caution.

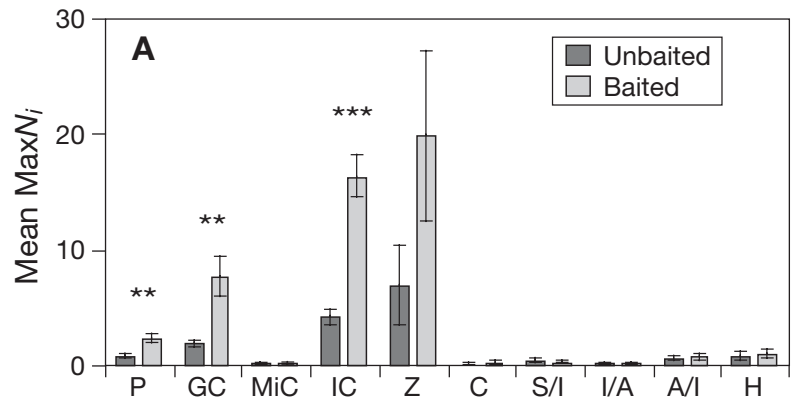

\section{Tropical trophic groups}

In the tropical data, a 2-way non-parametric multivariate analysis of variance (PERMANOVA) showed significantly higher mean numbers of individuals $\left(\operatorname{Max} N_{i i}\right.$ Fig. 4A) and species ( $N_{\text {spi }}$ Fig. 4B) were recorded by baited RUVS for piscivores, generalist carnivores and invertebrate carnivores in comparison to unbaited RUVS (Table 5, Fig. 4A,B). For Max $N_{i}$ there were significant differences between habitats for 6 of the 10 trophic groups (exceptions being generalist carnivores, macroinvertebrate carnivores, corallivores and invertebrates/algae). A similar pattern was seen for $N_{\mathrm{sp}}$, with no significant differences recorded be-

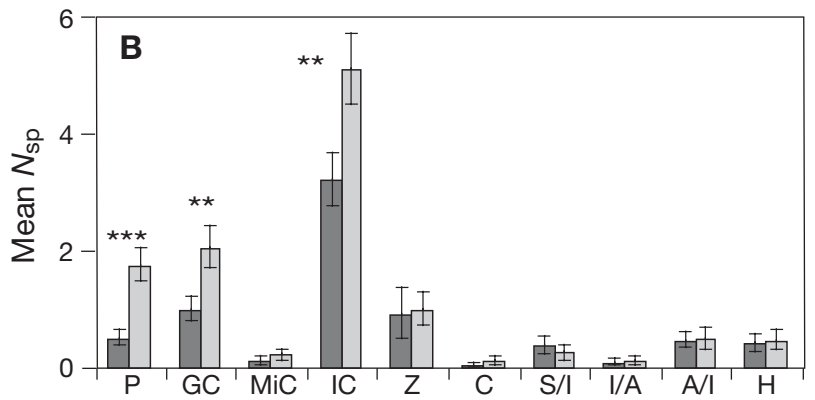

Fig. 4. Tropical assemblage: mean (A) Max $N_{i}$ and (B) $N_{\mathrm{sp}}$ counted for both unbaited and baited RUVS for 10 trophic groups within 4 benthic habitats; $\mathrm{N}=6$. P: piscivore; GC: generalist carnivore; MIC: macroinvertebrate carnivore; IC: invertebrate carnivore; Z: zooplankton; C: corallivores; S/I: sponge invertebrates; I/A: invertebrates/algae; A/I: algae/invertebrates; H: herbivores. Error bars: \pm 1 SE. Asterisk indicates the level of significance for treatment (baited vs. unbaited). ${ }^{*} p<0.05,{ }^{* *} p<0.01,{ }^{* * *} p<0.001$ 
Table 4. Temperate assemblage: the results of PERMANOVA tests for differences in numbers of individuals $\left(\operatorname{Max} N_{i}\right)$ and species $\left(N_{\mathrm{sp}}\right)$ between baited and unbaited RUVS (T: treatment) for trophic groups in 6 habitats $(\mathrm{H}) ; \mathrm{N}=4$ baited and 4 unbaited RUVS per habitat. Bold values: $\mathrm{p}<0.05$

\begin{tabular}{|c|c|c|c|c|c|c|c|}
\hline \multirow[t]{2}{*}{ Source } & \multirow[t]{2}{*}{ df } & \multicolumn{3}{|c|}{ Individuals $\left(\operatorname{Max} N_{i}\right)$} & \multicolumn{3}{|c|}{ Species $\left(N_{\mathrm{sp}}\right)$} \\
\hline & & MS & $F$ & $\mathrm{p}$ & MS & $F$ & $\mathrm{p}$ \\
\hline \multicolumn{8}{|l|}{ Piscivore } \\
\hline $\mathrm{T}$ & 1 & 3.285 & 5.123 & 0.024 & 2.408 & 11.890 & 0.002 \\
\hline $\mathrm{H}$ & 5 & 1.340 & 2.090 & 0.081 & 0.413 & 2.038 & 0.100 \\
\hline $\mathrm{T} \times \mathrm{H}$ & 5 & 0.228 & 0.355 & 0.885 & 0.046 & 0.229 & 0.946 \\
\hline Residual & 36 & 0.641 & & & 0.203 & & \\
\hline Total & 47 & & & & & & \\
\hline \multicolumn{8}{|c|}{ Generalist carnivore } \\
\hline $\mathrm{T}$ & 1 & 4.521 & 12.029 & 0.027 & 2.515 & 19.800 & $<0.001$ \\
\hline $\mathrm{H}$ & 5 & 0.927 & 2.466 & 0.053 & 0.498 & 3.919 & 0.008 \\
\hline $\mathrm{T} \times \mathrm{H}$ & 5 & 0.173 & 0.461 & 0.814 & 0.135 & 1.061 & 0.417 \\
\hline Residual & 36 & 0.376 & & & 0.127 & & \\
\hline Total & 47 & & & & & & \\
\hline \multicolumn{8}{|c|}{ Macroinvertebrate carnivore } \\
\hline $\mathrm{T}$ & 1 & 0.842 & 5.100 & 0.027 & 0.873 & 6.142 & 0.018 \\
\hline $\mathrm{H}$ & 5 & 0.245 & 1.486 & 0.224 & 0.205 & 1.440 & 0.233 \\
\hline $\mathrm{T} \times \mathrm{H}$ & 5 & 0.094 & 0.571 & 0.721 & 0.092 & 0.649 & 0.659 \\
\hline Residual & 36 & 0.165 & & & 0.142 & & \\
\hline Total & 47 & & & & & & \\
\hline \multicolumn{8}{|c|}{ Invertebrate carnivore } \\
\hline $\mathrm{T}$ & 1 & 6.734 & 15.592 & $<0.001$ & 2.717 & 18.019 & $<0.001$ \\
\hline $\mathrm{H}$ & 5 & 4.640 & 10.744 & $<0.001$ & 1.841 & 12.209 & $<0.001$ \\
\hline $\mathrm{T} \times \mathrm{H}$ & 5 & 0.150 & 0.347 & 0.881 & 0.131 & 0.870 & 0.506 \\
\hline Residual & 36 & 0.432 & & & 0.151 & & \\
\hline Total & 47 & & & & & & \\
\hline \multicolumn{8}{|c|}{ Zooplanktivore } \\
\hline $\mathrm{T}$ & 1 & 1.026 & 1.903 & 0.179 & 0.434 & 3.037 & 0.087 \\
\hline $\mathrm{H}$ & 5 & 3.129 & 5.807 & 0.002 & 1.350 & 9.445 & $<0.001$ \\
\hline $\mathrm{T} \times \mathrm{H}$ & 5 & 0.579 & 1.075 & 0.388 & 0.118 & 0.824 & 0.533 \\
\hline Residual & 36 & 0.539 & & & 0.143 & & \\
\hline Total & 47 & & & & & & \\
\hline \multicolumn{8}{|c|}{ Invertebrates/Algae } \\
\hline $\mathrm{T}$ & 1 & 4.323 & 4.744 & 0.036 & 1.178 & 7.225 & 0.014 \\
\hline $\mathrm{H}$ & 5 & 6.426 & 7.050 & $<0.001$ & 2.388 & 14.650 & $<0.001$ \\
\hline $\mathrm{T} \times \mathrm{H}$ & 5 & 0.810 & 0.888 & 0.490 & 0.149 & 0.915 & 0.479 \\
\hline Residual & 36 & 0.911 & & & 0.163 & & \\
\hline Total & 47 & & & & & & \\
\hline \multicolumn{8}{|c|}{ Algae/Invertebrates } \\
\hline $\mathrm{T}$ & 1 & 0.000 & 0.000 & 1.000 & 0.002 & 0.071 & 0.816 \\
\hline $\mathrm{H}$ & 5 & 1.817 & 54.940 & $<0.001$ & 1.552 & 64.178 & $<0.001$ \\
\hline $\mathrm{T} \times \mathrm{H}$ & 5 & 0.004 & 0.125 & 0.985 & 0.002 & 0.071 & 0.995 \\
\hline Residual & 36 & 0.033 & & & 0.024 & & \\
\hline Total & 47 & & & & & & \\
\hline \multicolumn{8}{|c|}{ Herbivores } \\
\hline $\mathrm{T}$ & 1 & 0.241 & 3.540 & 0.069 & 0.067 & 2.446 & 0.104 \\
\hline $\mathrm{H}$ & 5 & 0.336 & 4.930 & 0.007 & 0.124 & 4.545 & $<0.001$ \\
\hline $\mathrm{T} \times \mathrm{H}$ & 5 & 0.383 & 5.625 & 0.003 & 0.153 & 5.595 & 0.003 \\
\hline Residual & 36 & 0.068 & & & 0.027 & & \\
\hline Total & 47 & & & & & & \\
\hline
\end{tabular}

recorded in unbaited RUVS in near benthos habitats. Similarly, with invertebrates/algae, a Treatment $\times$ Habitat interaction was caused by a greater number of individuals being recorded in unbaited RUVS in coarse sediments.

\section{DISCUSSION}

The use of bait increased the ability of RUVS to discriminate fish assemblages in distinctive benthic habitats in tropical and temperate Australia. This was due to the increased numbers of individuals and species sampled at the baited stations. Similarly, there were also increasing trends evident in the number of species and individuals in approximately half of the trophic groups, which is contrary to the expectations from previous trapping studies (Munro 1974). This is an important outcome for researchers interested in assessing demersal fish biodiversity.

Fish trapping studies have shown that herbivorous siganids and scarids dominate catches of unbaited traps on coral reefs, yet these families seldom appear in baited traps (Munro 1974, Newman 1990). Furthermore, it could be argued that the predators and scavengers attracted to the baited fish traps or RUVS might interact with non-predatory or herbivorous species, resulting in a reduced number of individuals, species and trophic groups being recorded. Of particular interest in our study is the finding that there was no statistically significant difference between the baited and unbaited RUVS for the numbers and diversity of fish sampled in the herbivorous or invertebrate/algae trophic groups. The use of bait did not deter fish from these trophic groups being recorded in the field of view. Instead, baited RUVS sampled more herbivorous species in temperate and tropical habitats and more individuals in tropical habitats (MaxN for herbivores was identical in temperate habitats) than the unbaited RUVS. This is an important finding that contradicts the outcomes of some trapping studies, which have found that relative tween habitats for the macroinvertebrate carnivores, corallivores and invertebrates/algae trophic groups.

There was also a significant Treatment $\times$ Habitat interaction for macroinvertebrate carnivores for $\operatorname{Max} N_{i}$ and $N_{\mathrm{sp}}$, with more individuals and species being abundances of herbivorous fish decrease when bait is set as a fish attractant.

Our observations of fish behaviour during the tape analysis showed that herbivorous species did not readily approach the camera or the bait canister, but 
Table 5. Tropical assemblage: the results of PERMANOVA tests for differences in the numbers of individuals $\left(\operatorname{Max} N_{i}\right)$ and species $\left(N_{\mathrm{sp}}\right)$ between baited and unbaited RUVS (T: treatment) for trophic groups in 4 habitats $(\mathrm{H}) ; \mathrm{N}=6$ baited and 6 unbaited RUVS per habitat. Bold values: $\mathrm{p}<0.05$

\begin{tabular}{|c|c|c|c|c|c|c|c|}
\hline \multirow[t]{2}{*}{ Source } & \multirow[t]{2}{*}{$\mathrm{df}$} & \multicolumn{3}{|c|}{ Individuals $\left(\operatorname{Max} N_{i}\right)$} & \multicolumn{3}{|c|}{ Species $\left(N_{\mathrm{sp}}\right)$} \\
\hline & & MS & $F$ & $\mathrm{p}$ & MS & $F$ & $\mathrm{p}$ \\
\hline \multicolumn{8}{|l|}{ Piscivore } \\
\hline $\mathrm{T}$ & 1 & 4.713 & 14.451 & $<0.001$ & 3.607 & 16.111 & $<0.001$ \\
\hline $\mathrm{H}$ & 5 & 1.134 & 3.477 & 0.025 & 0.680 & 3.036 & 0.042 \\
\hline $\mathrm{T} \times \mathrm{H}$ & 5 & 0.029 & 0.090 & 0.962 & 0.013 & 0.057 & 0.979 \\
\hline Residual & 36 & 0.326 & & & 0.224 & & \\
\hline Total & 47 & & & & & & \\
\hline \multicolumn{8}{|c|}{ Generalist carnivore } \\
\hline $\mathrm{T}$ & 1 & 9.958 & 13.347 & $<0.001$ & 1.746 & 8.430 & 0.006 \\
\hline $\mathrm{H}$ & 5 & 0.468 & 0.627 & 0.600 & 0.732 & 3.533 & 0.029 \\
\hline $\mathrm{T} \times \mathrm{H}$ & 5 & 0.269 & 0.361 & 0.777 & 0.538 & 2.599 & 0.063 \\
\hline Residual & 36 & 0.746 & & & 0.207 & & \\
\hline Total & 47 & & & & & & \\
\hline \multicolumn{8}{|c|}{ Macroinvertebrate carnivore } \\
\hline $\mathrm{T}$ & 1 & 0.040 & 0.769 & 0.252 & 0.040 & 0.769 & 0.257 \\
\hline $\mathrm{H}$ & 5 & 0.080 & 1.539 & 0.226 & 0.080 & 1.539 & 0.206 \\
\hline $\mathrm{T} \times \mathrm{H}$ & 5 & 0.280 & 5.385 & 0.004 & 0.280 & 5.385 & 0.004 \\
\hline Residual & 36 & 0.052 & & & 0.052 & & \\
\hline Total & 47 & & & & & & \\
\hline \multicolumn{8}{|c|}{ Invertebrate carnivore } \\
\hline $\mathrm{T}$ & 1 & 17.147 & 37.683 & $<0.001$ & 1.459 & 7.028 & 0.013 \\
\hline $\mathrm{H}$ & 5 & 1.416 & 3.111 & 0.042 & 1.901 & 9.157 & 0.000 \\
\hline $\mathrm{T} \times \mathrm{H}$ & 5 & 0.152 & 0.333 & 0.793 & 0.328 & 1.580 & 0.213 \\
\hline Residual & 36 & 0.455 & & & 0.208 & & \\
\hline Total & 47 & & & & & & \\
\hline \multicolumn{8}{|c|}{ Zooplanktivore } \\
\hline $\mathrm{T}$ & 1 & 8.306 & 4.246 & 0.051 & 0.206 & 0.897 & 0.341 \\
\hline $\mathrm{H}$ & 5 & 7.444 & 3.805 & 0.017 & 1.532 & 6.658 & 0.001 \\
\hline $\mathrm{T} \times \mathrm{H}$ & 5 & 4.366 & 2.232 & 0.093 & 0.797 & 3.466 & 0.023 \\
\hline Residual & 36 & 1.956 & & & 0.230 & & \\
\hline Total & 47 & & & & & & \\
\hline \multicolumn{8}{|c|}{ Corallivores } \\
\hline $\mathrm{T}$ & 1 & 0.058 & 0.719 & 0.434 & 0.040 & 1.111 & 0.394 \\
\hline $\mathrm{H}$ & 5 & 0.121 & 1.488 & 0.203 & 0.080 & 2.222 & 0.180 \\
\hline $\mathrm{T} \times \mathrm{H}$ & 5 & 0.036 & 0.446 & 0.786 & 0.013 & 0.370 & 0.770 \\
\hline Residual & 36 & 0.081 & & & 0.036 & & \\
\hline Total & 47 & & & & & & \\
\hline \multicolumn{8}{|c|}{ Sponges/Invertebrates } \\
\hline $\mathrm{T}$ & 1 & 0.090 & 0.671 & 0.396 & 0.058 & 0.463 & 0.493 \\
\hline $\mathrm{H}$ & 5 & 0.600 & 4.473 & 0.007 & 0.544 & 4.313 & 0.009 \\
\hline $\mathrm{T} \times \mathrm{H}$ & 5 & 0.037 & 0.273 & 0.844 & 0.021 & 0.163 & 0.929 \\
\hline Residual & 36 & 0.134 & & & 0.126 & & \\
\hline Total & 47 & & & & & & \\
\hline \multicolumn{8}{|c|}{ Invertebrates/Algae } \\
\hline $\mathrm{T}$ & 1 & 0.002 & 0.031 & 0.777 & 0.010 & 0.238 & 0.447 \\
\hline $\mathrm{H}$ & 5 & 0.052 & 0.945 & 0.425 & 0.037 & 0.873 & 0.438 \\
\hline $\mathrm{T} \times \mathrm{H}$ & 5 & 0.155 & 2.833 & 0.046 & 0.117 & 2.778 & 0.075 \\
\hline Residual & 36 & 0.055 & & & 0.042 & & \\
\hline Total & 47 & & & & & & \\
\hline \multicolumn{8}{|c|}{ Algae/Invertebrates } \\
\hline $\mathrm{T}$ & 1 & 0.004 & 0.018 & 0.886 & 0.002 & 0.011 & 0.867 \\
\hline $\mathrm{H}$ & 5 & 0.970 & 4.300 & 0.012 & 0.656 & 4.050 & 0.012 \\
\hline $\mathrm{T} \times \mathrm{H}$ & 5 & 0.157 & 0.697 & 0.556 & 0.113 & 0.698 & 0.557 \\
\hline Residual & 36 & 0.226 & & & 0.162 & & \\
\hline Total & 47 & & & & & & \\
\hline \multicolumn{8}{|c|}{ Herbivores } \\
\hline $\mathrm{T}$ & 1 & 0.079 & 0.342 & 0.573 & 0.003 & 0.037 & 0.815 \\
\hline $\mathrm{H}$ & 5 & 3.226 & 13.976 & $<0.001$ & 1.607 & 17.279 & $<0.001$ \\
\hline $\mathrm{T} \times \mathrm{H}$ & 5 & 0.096 & 0.417 & 0.740 & 0.030 & 0.324 & 0.820 \\
\hline Residual & 36 & 0.231 & & & 0.093 & & \\
\hline Total & 47 & & & & & & \\
\hline
\end{tabular}

tended to be visible 4 to $7 \mathrm{~m}$ beyond the bait basket grazing or swimming by. Baited RUVS record species of fish that were attracted to the bait plume; species attracted to the structure of the RUVS; species attracted by the activity of other fish feeding and aggregating around the RUVS; species occupying territories within the field of view of the camera; and species indifferent to the station, but present in, or passing through, the field of view during the deployment. The results presented here show that the use of bait in the field of view facilitates greater discrimination of fish assemblages between habitats, but also increases the similarity of samples within a habitat. Increased similarity between replicate samples within a habitat will improve the statistical power of detecting changes in fish populations at the assemblage level.

Sampling more individuals of a single species has several advantages. Firstly, the variances of individual species sampled within habitats decreased when RUVS were used with bait. This was particularly important for the large generalist carnivores, macroinvertebrate carnivores and piscivores, which are mobile and have relatively low densities and patchy distributions. Fewer 'false negatives' and a lower variance imply better statistical power to detect differences amongst samples (Willis \& Babcock 2000, Watson et al. 2005). Additionally, attracting more individuals of a single species closer to the camera system will provide better opportunities to obtain precise and accurate measurements of length using stereo-video systems (Harvey \& Shortis 1996, Harvey et al. 2002a,b). Length measurements can facilitate discrimination between individuals and may facilitate new ways of assessing all individuals of a species seen on a recording. Without these measurements, $\operatorname{Max} N$ will remain a conservative estimate of relative abundance (Willis \& Babcock 2000).

Like all fish sampling techniques, questions remain about the biases of baited underwater cameras in measuring species richness, diversity and relative abundances. Whilst baited RUVS eliminate much of the selectivity associated with extractive fishing gears, they are also likely to introduce other biases because of the multiplicity of behaviours adopted by demersal fishes (Armstrong et al. 1992). The only means to discern the 
biases associated with baited RUVS are to compare the technique with underwater visual census (UVC) by divers in shallow waters (Willis et al. 2000, Watson et al. 2005) and with common extractive techniques in deeper waters, such as trawling (e.g. Priede \& Merrett 1996, Cappo et al. 2004), long-lining (Ellis \& DeMartini 1995) and trapping. In this way, Watson et al. (2005) showed that bait increased the sampling power of RUVS, and that use of UVC and baited RUVS supplemented the overall assessment of biodiversity.

One of the key issues yet to be addressed by users of baited RUVS in continental shelf waters is the distance over which fish may be attracted to the bait. Studies using baited RUVS targeting deepwater scavengers (e.g. Priede \& Merrett 1996) have modelled the area of attraction using $\operatorname{Max} N$ and arrival time, in conjunction with knowledge of current velocities, fish swimming speeds and models of bait plume behaviour, to estimate absolute density. These numerically sophisticated approaches require a number of unverifiable assumptions, and results are not amenable to robust falsification. In contrast, users of baited RUVS on shelf and coastal reefs have ignored plume dispersal, and utilised various calibrations of abundance indices during short sets (10 to $90 \mathrm{~min}$ ) to estimate patterns of relative abundance (e.g. Ellis \& DeMartini 1995, Willis $\&$ Babcock 2000). However, some attempts have been made to avoid overlap of the plumes among baited RUVS, to ensure that replicates are independent of one another (see Cappo et al. 2004).

Different types of bait may influence the numbers of individuals and species attracted to the bait and the distance over which a fish is attracted. The effect of bait type in RUVS can be inferred from previous studies on the catch rates of fish traps and baited hooks. Oily, soft-fleshed baits, such as clupeid baitfish, are clearly superior (4 to 5 times more effective) to whitefleshed baits (Whitelaw et al. 1991) and octopus (High 1980), in terms of attractiveness to fish. Similarly, the probability of arrival of a fish at the baited trap or hook has been reported to be governed by the size, type and freshness of the bait, and the search pattern, appetite and response time of the fish (e.g. Miller 1983, Lokkeborg \& Bjordal 1992). Therefore, if baited RUVS are to be used for sampling involving temporal or spatial comparisons then the type of bait, the quantity of bait used and delivery should be standardised. Seasonal, reproductive and lunar patterns of activity in the swimming speed, schooling behaviour and appetite of the fish presumably also affect the attraction of fish to a bait, as will conspecific attraction, curiosity, the presence or absence of predators and home range sizes (Munro 1974, Newman 1990).

The results presented here indicate that baited remote underwater video stations (BRUVS) are capable of recording fishery-independent data on demersal fish assemblages that is robust and reproducible. If standardised camera designs, field techniques (including bait type and quantity) and video analysis techniques are used, future studies should be comparable spatially and temporally, even if collected by different research groups. The key challenge is ensuring that the areas or volumes within which fish are counted are defined and consistent, requiring the use of stereovideo techniques (Harvey et al. 2004).

Acknowledgements. The authors acknowledge grants and financial aid from the Fisheries Research and Development Corporation (FRDC 97/205, FRDC 2001/060) and the Coastal and Estuary Waterway Management Cooperative Research Centre. E.S.H. was supported by a postdoctoral fellowship from the University of Western Australia. We would like to acknowledge and thank D. Gull, T. Wassenberg and P. Speare, who assisted with field work and the analysis of video tape recordings, and T. Langlois and D. Watson for constructive reviews of this manuscript.

\section{LITERATURE CITED}

Anderson MJ (2001) A new method for non-parametric multivariate analysis of variance. Austral Ecol 26:32-46

Anderson MJ, Gorley RN (2007) PERMANOVA+ for PRIMER: guide to software and statistical methods. PRIMER-E, Plymouth

Anderson MJ, Millar RB (2004) Spatial variation and effects of habitat on temperate reef fish assemblages in northeastern New Zealand. J Exp Mar Biol Ecol 305:191-221

Anderson MJ, Robinson J (2003) Generalised discriminant analysis based on distances. Aust NZ J Stat 45:301-318

Anderson MJ, Willis TJ (2003) Canonical analysis of principle coordinates: a useful method of constrained ordination for ecology. Ecology 84:511-525

Armstrong JD, Bagley PM, Priede IG (1992) Photographic and acoustic tracking observations of the behaviour of the grenadier Coryphaenoides (Nematonurus) armatus, the eel Synaphobranchus bathybius, and other abyssal demersal fish in the North Atlantic Ocean. Mar Biol 112: $535-544$

Cappo M, Harvey E, Malcolm H, Speare P (2003) Potential of video techniques to monitor diversity, abundance and size of fish in studies of Marine Protected Areas. In: Beumer JP, Grant A, Smith DC (eds) Aquatic protected areas-What works best and how do we know? Proc World Congr on Aquat Protected Areas. Australian Society for Fish Biology, North Beach, Western Australia, p 455-464

Cappo M, Speare P, D'eath G (2004) Comparison of Baited Remote Underwater Video Stations (BRUVS) and prawn (shrimp) trawls for assessments of fish biodiversity in interreefal areas of the Great Barrier Reef Marine Park. J Exp Mar Biol Ecol 302:123-152

Denny CM, Babcock RC (2004) Do partial marine reserves protect reef fish assemblages? Biol Conserv 116:119-129

Denny CM, Willis TJ, Babcock RC (2004) Rapid recolonisation of snapper Pagrus auratus: Sparidae within an offshore island marine reserve after implementation of no-take status. Mar Ecol Prog Ser 272:183-190

Ellis DM, DeMartini EE (1995) Evaluation of a video camera technique for indexing the abundances of juvenile pink 
snapper, Pristipomoides filamentosus, and other Hawaiian insular shelf fishes. Fish Bull (Wash DC) 93:67-77

Froese R, Pauly D (2006) (eds) Fishbase. Available at www. fishbase.org

Harvey ES, Shortis MR (1996) A system for stereo-video measurement of sub-tidal organisms. Mar Technol Soc J 29:10-22

Harvey ES, Shortis MR, Stadler M, Cappo M (2002a) A comparison of the accuracy and precision of digital and analogue stereo-video systems. Mar Technol Soc J 36:38-49

Harvey ES, Fletcher D, Shortis MR (2002b) Estimation of reef fish length by divers and by stereo-video. A first comparison of the accuracy and precision in the field on living fish under operational conditions. Fish Res 57:255-265

Harvey ES, Fletcher D, Shortis MR, Kendrick GA (2004) A comparison of underwater visual distance estimates made by SCUBA divers and a stereo-video system: implications for underwater visual census of reef fish abundance. Mar Freshw Res 55:573-580

High WL (1980) Bait loss from halibut longline gear observed from a submersible. Mar Fish Rev 42:26-29

Kulbicki M (1998) How the acquired behaviour of commercial reef fishes may influence the results obtained from visual censuses. J Exp Mar Biol Ecol 222:11-30

Lokkeborg S, Bjordal A (1992) Species and size selectivity in longline fishing: a review. Fish Res 13:311-322

Miller RJ (1983) Methods for field experiments with baited traps. J Shellfish Res 3:97-98

Munro JL (1974) The mode of operation of Antillean Z traps and the relationships between ingress, escapement, catch and soak. J Cons Int Explor Mer 35:337-350

Newman SJ (1990) Effects of depth of set, mesh size, bait and lunar phase on the performance of fish traps on the Great Barrier Reef. BSc (Hons) thesis, James Cook University of North Queensland, Townsville

Priede IG, Merrett NR (1996) Estimation of abundance of abyssal demersal fishes; a comparison of data from trawls and baited cameras. J Fish Biol 49 (Suppl A):207-216

Priede IG, Smith KL, Armstrong JD (1990) Foraging behaviour of abyssal grenadier fish: inferences from acoustic tagging and tracking in the North Pacific Ocean. DeepSea Res 37:81-101

Editorial responsibility: Howard Browman (Associate Editorin-Chief), Storebø, Norway
Priede IG, Bagley PM, Smith A, Creasey S, Merrett NR (1994) Scavenging deep demersal fishes of the Porcupine Seabight, north-east Atlantic: observations by baited camera, trap and trawl. J Mar Biol Assoc UK 74:481-498

Samoilys MA, Carlos G (2000) Determining methods of underwater visual census for estimating the abundance of coral reef fishes. Environ Biol Fishes 57:289-304

Stewart BD, Beukers JS (2000) Baited technique improves censuses of cryptic fish in complex habitats. Mar Ecol Prog Ser 197:259-272

Watson RA, Carlos GM, Samoilys MA (1995) Bias introduced by the non-random movement of fish in visual transect surveys. Ecol Model 77:205-214

Watson DL, Harvey ES, Anderson MJ, Kendrick GA (2005) A comparison of temperate reef fish assemblages recorded by three underwater stereo-video techniques. Mar Biol 148:415-425

Westera M, Lavery P, Hyndes G (2003) Differences in recreationally targeted fishes between protected and fished areas of a coral reef marine park. J Exp Mar Biol Ecol 294:145-168

Whitelaw AW, Sainsbury KJ, Dews GJ, Campbell RA (1991) Catching characteristics of four fish-trap types on the north west shelf of Australia. Aust J Mar Freshwater Res 42:369-382

Williams DMcB, Fowler AJ, Newman SJ (1997) Development of trap and drop-line sampling techniques for reef fishes: a report to Great Barrier Reef Marine Park Authority. Research Publication No. 43, Great Barrier Reef Marine Park Authority, Townsville, Queensland

Willis TJ, Babcock RC (2000) A baited underwater video system for the determination of relative density of carnivorous reef fish. Mar Freshw Res 51:755-763

Willis TJ, Millar RB, Babcock RC (2000) Detection of spatial variability in relative density of fishes: comparison of visual census, angling and baited underwater video. Mar Ecol Prog Ser 198:249-260

Yoklavich MM, Greene HG, Cailliet GM, Sullivan DE, Lea RN, Love MS (2000) Habitat associations of deep-water rockfishes in a submarine canyon: an example of a natural refuge. Fish Bull (Wash DC) 98:625-641

Submitted: December 7, 2006; Accepted: July 27, 2007 Proofs received from author(s): November 11, 2007 